\title{
Coal Waste as Raw Material for Production of Rare and Trace Elements
}

\author{
Cherkasova Tatiana G. ${ }^{\mathrm{a}}$, Cherkasova Yelizaveta V. ${ }^{\mathrm{b}}$ Tikhomirova Anastasia V. ${ }^{\mathrm{c}}$, Bobrovnikova Alyona A. ${ }^{\mathrm{d}}$, \\ Papin Andrey V. ${ }^{\mathrm{e}}$, Nevedrov Aleksandr V. ${ }^{\mathrm{f}}$ \\ T.F. Gorbachev Kuzbass State Technical University \\ Kemerovo, Russian Federation \\ actg.htnv@kuzstu.ru, bcherkasovaliza@mail.ru, csquirrel_mink@mail.ru, dbobrownickowa.al@yandex.ru, \\ epapinandrey@rambler.ru, ${ }^{\mathrm{f}}$ nevedrov1978@ rambler.ru
}

\begin{abstract}
Huge masses of coal wastes create serious environmental problems in the Kemerovo region and require a comprehensive approach to the development of deposits. Coal must be considered as a complex raw material, which contains valuable rare and trace metals, the recovery of which creates products with high added value. Production of rare earth elements is limited, since it is associated with considerable complexity and costliness of existing extraction processes. Therefore, the development of new methods for the preparation of rare earth products based on the study of physical and chemical characteristics and laws of the processes occurring in the extraction and separation of rare earth elements is of great importance. This paper presents an overview of sources of rare earth elements, and the feasibility of the efficient extraction of rare earth elements from slag and fly ash of Kemerovo hydroelectric power plant by ion flotation is proved.
\end{abstract}

Keywords - slag, sludge; low-grade coal; the extraction of rare and trace elements.

\section{INTRODUCTION}

Kuzbass is, above all, the coal region. Coal, being one of the most exploited natural energy resources, now often is simply burned; in the best case it undergoes a simple mechanical enrichment before burning. For 1 ton of coal recovered by open-pit mining the average of 4 tons of overburden are produced, underground mining gives 200-300 $\mathrm{kg}$ of waste rock and $200-300 \mathrm{~kg}$ of tailings. Taking into account the average ash content of Kuzbass coal 100-150 kg of ash and slag can be added to these volumes. Such masses of waste create the serious environmental problems and require a comprehensive approach to the development of deposits. The traditional use of coal threatens the environment of the region: the territory of the Kemerovo region is overloaded by coal combustion waste tens of millions of tons of which are produced annually. The necessity to study the metal content of coals is due to the fact that they accumulate, sometimes in significant quantities, commercially valuable or environmentally hazardous elements [1-3]. The increased requirements for environmental safety of fuel energy, coke and other industries using the coal feedstock, also call for its comprehensive and in-depth evaluation. This is especially relevant to the harmful impurities. The significant amount of potentially hazardous elements is accumulated in the ash waste. The coal dumps constantly raise dust, the mobile forms of elements are actively washed out by precipitation, polluting water, air, soil, and vegetation. [4]. The storage of 1 ton of slag waste costs for the state \$ 70-100 per year. Ash and slag mass of coal are, in fact, the separate ore deposits located on the surface and not requiring their extraction costs. It is necessary to consider coal as a complex raw material, which contains valuable chemicals.

It is known that the geochemical content, for example, of lithium in the Kuznetsk coal is three and a half times higher than the global figure, of hafnium - is twice of that.

The data on metals, which are traditionally in high and stable demand on the world market are especially attractive to practitioners, it is, for example, titanium, the content of which reaches $1-14 \%$ per ton, niobium which content in the ash of the Kuzbass coal reaches one or more kilograms per ton.

The development of highly selective technologies for the recovery of rare, trace and rare earth elements (REEs) from all possible sources and creation of new functional materials on their basis are relevant objectives from both the economic and the environmental points of view [5-21].

The profitability of coal processing waste will be higher if not only isolated elements but their complexes will be removed, including most rare, rare earth and precious metals; the more so, because the proven reserves of Kuznetsk coal contain more than 55 of the periodic table of elements from lithium to uranium.

\section{MATERIALS AND METHODS}

The objects of study are the slag and fly ash of Kemerovo hydro-electric power plant.

The batches of slag were milled to a particle size of 0.2 $\mathrm{mm}$. The analyses on the content of chemical components were carried out by optical emission spectroscopy with the inductively coupled plasma using the iCAP 6500DIO spectrometer and consisted of the following stages:

1) preparation of solid sampling;

2) aqua regia extraction;

3) analysis of the compact;

4) analysis of the extract. 
For the isolation and separation of the components the method of ion flotation was used.

The method is applicable for the extraction of substances from the solutions with a concentration of up to one hundred million moles per liter. Ion flotation is based on the extracted ion attraction oppositely by the charged ions of the collector, which is fixed on the surface of air or gas bubbles passed through the solution. The ion flotation has two possible mechanisms: adsorption and adhesion. In the first case, the floated substance is concentrated on the surface of the bubble as a result of the adsorption. In the case the precipitate adhering to the bubbles is formed. Ion flotation is different from other known methods of extraction - the extraction and adsorption - in selectiveness, simplicity, high speed, efficiency, even at the low concentrations of the components, resulting in more efficient technologies, thanks to the simultaneous extraction of valuable components. For the selective separation of metal cations from the aqueous solutions it is necessary to choose the right settings of flotation machine. The ion flotation is affected by the height and volume of the apparatus, the flotation duration, the air or the gas flow rate and the bubble size.

We used an anionic surfactant (SAW) - sodium dodecyl sulfate $\left(\mathrm{C}_{12} \mathrm{H}_{25} \mathrm{SO}_{4} \mathrm{Na}\right.$ - lauryl acid sodium salt), which combines the properties of a collector and frother. This choice is due to its wide prevalence in the flotation technologies, low cost, non-toxicity, the ease of use.

\section{RESULTS AND DISCUSSION}

The data of the analysis of the study objects is presented in Tables 1, 2.

The ash contains a large quantity of iron, that's why magnetic separation was carried out; it was found that the magnetic fraction represents about $20 \%$ of the waste mass. The aluminosilicate microspheres, silica $\left(\mathrm{SiO}_{2}\right)$, alumina $\left(\mathrm{Al}_{2} \mathrm{O}_{3}\right)$, alkaline earth metal oxides $(\mathrm{CaO}, \mathrm{MgO})$ are of the main commercial interest among the non-magnetic components $(80 \%)$.

The main method of primary processing of coal and ash waste is their opening by the chemical acid reagents, such as the mineral acids or organic H+- cations and the subsequent leaching of solutions. We tested the nitric and sulfuric acids as the reagent for the opening of the raw materials. The sulfuric acid is preferred because it does not leach the sulfates of many associated elements. Furthermore, we carried out the sodium hydroxide solution leaching and the sodium fusion.

From these data (Tables 1,2) it is obvious that the content of rare and trace metals in the studied objects is lower by 1-2 orders of magnitude than that in the minerals, in particular, in the rare earths minerals (monazite: $264-280 \mathrm{~g} / \mathrm{t}$, loparite: $112-$ $180 \mathrm{~g} / \mathrm{t}$ ). Therefore the ash and slag treatment was carried out by ion flotation method aiming to the further extraction of rare and rare earth element compounds. The obtained results for the content of rare and trace elements in the concentrates are shown in Table 3.
TABLE I. THE CONTENT OF RARE, TRACE AND RARE EARTH ELEMENTS IN KEMEROVO HYDRO-ELECTRIC POWER PLANT SLAG

\begin{tabular}{|c|c|c|}
\hline \multirow{2}{*}{ Elements } & \multicolumn{2}{|c|}{ Content } \\
\cline { 2 - 3 } & $\boldsymbol{\%}$ & $\boldsymbol{g} / \boldsymbol{t}$ \\
\hline $\mathrm{Sr}$ & $1,9 \cdot 10^{-2}$ & 190,00 \\
\hline $\mathrm{Zr}$ & $4,7 \cdot 10^{-3}$ & 47,00 \\
\hline $\mathrm{Nb}$ & $8 \cdot 10^{-5}$ & 0,80 \\
\hline $\mathrm{Ga}$ & $1 \cdot 10^{-4}$ & 1,00 \\
\hline $\mathrm{Mo}$ & - & - \\
\hline $\mathrm{Au}$ & - & - \\
\hline $\mathrm{Ag}$ & $1 \cdot 10^{-5}$ & 0,10 \\
\hline $\mathrm{V}$ & $6,6 \cdot 10^{-4}$ & 6,60 \\
\hline $\mathrm{REEs}:$ & $3 \cdot 10^{-4}$ & \\
\hline $\mathrm{Y}$ & $1,5 \cdot 10^{-5}$ & 3,00 \\
\hline $\mathrm{Eu}$ & $4,7 \cdot 10^{-4}$ & 0,15 \\
\hline $\mathrm{La}$ & $1,7 \cdot 10^{-4}$ & 4,70 \\
\hline $\mathrm{Pr}$ & $1,1 \cdot 10^{-4}$ & 1,70 \\
\hline $\mathrm{Sm}$ & & 1,10 \\
\hline
\end{tabular}

TABLE II. THE CONTENT OF RARE, TRACE AND RARE EARTH ELEMENTS IN KEMEROVO HYDRO-ELECTRIC POWER PLANT FLY ASH

\begin{tabular}{|c|c|c|}
\hline \multirow{2}{*}{ Elements } & \multicolumn{2}{|c|}{ Content } \\
\cline { 2 - 3 } $\mathrm{Sr}$ & $1,1 \cdot 10^{-2}$ & $\boldsymbol{g} / \boldsymbol{t}$ \\
\hline $\mathrm{Zr}$ & $2,3 \cdot 10^{-4}$ & 2,30 \\
\hline $\mathrm{Nb}$ & $7,0 \cdot 10^{-4}$ & 7,00 \\
\hline $\mathrm{Ga}$ & $9,010^{-4}$ & 9,00 \\
\hline $\mathrm{Mo}$ & $8,7 \cdot 10^{-4}$ & 8,70 \\
\hline $\mathrm{Au}$ & $1,2 \cdot 10^{-4}$ & 1,20 \\
\hline $\mathrm{Ag}$ & - & - \\
\hline $\mathrm{V}$ & $5,3 \cdot 10^{-3}$ & 53,00 \\
\hline $\mathrm{REEs}:$ & $1,4 \cdot 10^{-3}$ & 14,00 \\
\hline $\mathrm{Y}$ & $6,8 \cdot 10^{-5}$ & 0,68 \\
\hline $\mathrm{Eu}$ & $1,9 \cdot 10^{-3}$ & 19,00 \\
\hline $\mathrm{La}$ & $7,0 \cdot 10^{-4}$ & 7,00 \\
\hline $\mathrm{Pr}$ & $1,5 \cdot 10^{-4}$ & 15,00 \\
\hline $\mathrm{Sm}$ & &
\end{tabular}

TABLE III. THE CONTENT OF RARE, TRACE AND RARE EARTH ELEMENTS IN THE CONCENTRATES

\begin{tabular}{|c|c|c|}
\hline Elements & $\begin{array}{c}\text { Concentrate 1 content, } \\
\boldsymbol{\%} / \mathbf{g} / \boldsymbol{t}\end{array}$ & $\begin{array}{c}\text { Concentrate } 2 \text { content, } \\
\boldsymbol{\%} / \mathbf{g} / \boldsymbol{t}\end{array}$ \\
\hline $\mathrm{Sr}$ & $2,7 \cdot 10^{-1} / 2700$ & $1,3 \cdot 10^{-1} / 1300$ \\
\hline $\mathrm{Zr}$ & $1 \cdot 10^{-1} / 100$ & $1,2 \cdot 10^{-1} / 1200$ \\
\hline $\mathrm{Nb}$ & $9 \cdot 10^{-3} / 90$ & $8,5 \cdot 10^{-3} / 85$ \\
\hline $\mathrm{Ga}$ & $5 \cdot 10^{-3} / 50$ & $4,8 \cdot 10^{-3} / 48$ \\
\hline $\mathrm{Mo}$ & $3 \cdot 10^{-2} / 300$ & $2 \cdot 10^{-2} / 200$ \\
\hline $\mathrm{V}$ & $2 \cdot 10^{-1} / 2000$ & $3 \cdot 10^{-1} / 3000$ \\
\hline$\Sigma \mathrm{REEs}$ & $8,5 \cdot 10^{-2} / 850$ & $7,7 \cdot 10^{-2} / 770$ \\
\hline
\end{tabular}




\section{CONCLUSION}

The concentrates produced by the rare earth element extraction method using sodium dodecyl sulfate are suitable for further processing - the separation of the elements. The extractable value of the metals from the coal and ash and slag mass is that they are hundred times more valuable than the coal as a fuel, as the modern high-tech industries are impossible without rare and rare earth metals.

An important aspect is also the improvement of the environmental situation in the region. Thus, the complex processing of coal connects the economy and the ecology (Fig. 1).

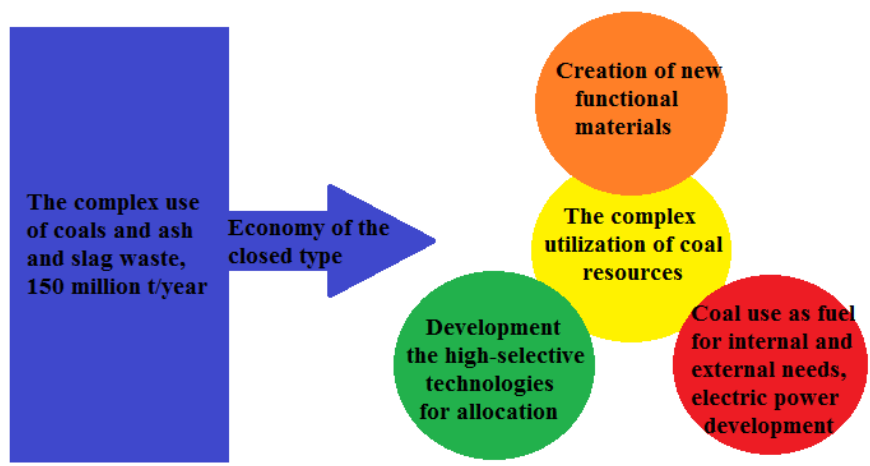

Fig. 1. Ecological chain of economy of the closed type - complex use of coals

\section{ACKNOWLEDGMENT}

The work was performed as part of the project of the state task № 10.782.2014K of the Ministry of Education and Science of the Russian Federation.

\section{REFERENCES}

[1] B.F. Nifantov, V.P. Potapov, N.V.Mitina, "Geochemistry and resources assessment of rare earth elements and radioactive elements in Kuznetsk coals," Prospect for processing,, 2003, pp: 104.

[2] V.V. Krapiventseva, "Metalliferous coals of Amur River region," Pacific geology, vol. 24, №1, 2005, pp: 73-84.

[3] M.D. Skurskiy, "Estimation of rare earth - rare metal - petro gas coal deposits in Kuzbass," Fuel \& Energy Complex and resources of Kuzbass, №2/15, 2004, pp: 24-30.
[4] A.A. Cherepanov, V.T. Kardash, "Complex processing of heating and power plant slag waste," Geology and mineral resources of the oceans, № 2, 2009, pp: 98-115.

[5] V.A. Salihov, "Scientific bases and improving of geological and economic assessment of useful components of coal deposits (on example of Kuzbass)," Kemerovo, Kuzbassvuzizdat, 2008, 249 p.

[6] M.I. Galimov, N.V. Granovskaya, S.V. Levchenko, "Metals in the coals," Rostov-on-Don: SFU, 2013, pp: 45.

[7] S.I. Arbuzov, V.V. Ershov, A.A. Potceluev, L.P. Rihvanov, "Rare elements in Kuzbass coals," Kemerovo, 1999, 248 p.

[8] S.I. Arbuzov, "Geochemistry of rare earth elements in coals of Central Siberia," Autor's abstract of doctor of technical science, Tomsk, 2005, pp: 40.

[9] S.I. Polkin, "Processing of ore and placer deposits of rare and precious metals," Moscow, Nedra, 1987, pp: 428.

[10] V.A. Salihov, "Prospects for the development of high-tech small enterprises (the case of Kemerovo region), " Bulletin of KemSU, №4, 2011, pp: 255-258.

[11] S.I. Arbuzov, "Metal content of Siberian coals," Bulletin of TPU, vol. 311, № 1, 2007, pp: 77-83.

[12] A.A.Yunash, "The development of new reactant treatments of coal flotation based on the use of sulfoxides and ethoxylated alkylphenols," G.I. Nosov Magnitogorsk State Technical University, 2004, MI.

[13] V.I. Rybalko, S.I. Arbuzov, "Forecast-geochemical assessment of Iran's coal metal content," Siberian Journal of Science, № 1(1), 2011, pp: 1922.

[14] P.A. Vlasov, "Geochemical features of the distribution of trace elements in coal processing waste of the dressing plant PF "Trudovskaya"," 2007, pp: 152-157.

[15] G.L. Pashkov, S.B. Saokova, V.I. Kuzmin, M.V. Panteleeva, A.N. Kokorina, E.V. Linok, "Natural coal ash - non-traditional raw material source of rare elements," Journal of Siberian Federal University, Engineering \& Technologies, 5, 2012, pp: 520-530.

[16] O.V. Afanasyeva, G.R. Mingaleeva, E.V. Shamsutdinov, S.U.Gorbuniv, "On the possibility of recovery of valuable non-ferrous and rare metals from ash waste," Ttatarstan power engineering, 3(39), 2015, pp: 41-45.

[17] O.V. Afanasyeva, G.R. Mingaleeva, A.D. Dobronravov, E.V. Shamsutdinov, "Integrated use of ash and slag waste. Proceedings of the higher educational institutions” Energy Issues, № 7-8, 2015, pp: 26-36.

[18] N.V. Fedorova, D.A. Shaforost, "Prospects for using the fly ash produced at thermal power plants in the Rostov region," Thermal Engineering, vol. 62, № 1, 2015, pp: 51-57.

[19] L.N. Adeeva, V.F. Borbar, "Heating and power plant ash - the promising raw material for the industry," Bulletin of Omsk University, №2, 2009, pp: 141-151.

[20] B.S. Ksenofontov, A.S. Kozodaev, V.A. Taranov, M.S. Vinodradov, I.A. Butorova, E.V. Senik, A.A. Voropaeva, "Leaching of rare earth metals from the fly ash of thermal power plants," Engineering Bulletin, №11, 2014, pp: 121.

[21] Y.G. Nazmeev, "Thermal power plant ash and slag removal systems," Moscow: Moscow Power Engineering Institute, 2002, pp: 572. 